\title{
Erratum
}

\section{Cognitive Function in Individuals with Normal Weight Obesity: Results from the Third National Health and Nutrition Examination Survey (NHANES III)}

Noemi Malandrino, Esmeralda Capristo, Tracey H. Taveira, Geltrude Mingrone and Wen-Chih Wu

[Journal of Alzheimer's Disease, 65(1)2018, 125-135, DOI 10.3233/JAD-180264]

https://content.iospress.com/articles/journal-of-alzheimers-disease/jad180264

On page 125, a single affiliation is given for Geltrude Mingrone: "Department of Internal Medicine, Catholic University of the Sacred Heart, Rome, Italy".

However, the following second affiliation should also have been present: "Fondazione Policlinico Universitario A. Gemelli IRCCS, Rome, Italia". 